\title{
Study of Prevalence and Antimicrobial Susceptibility Pattern of Matello- Beta-Lactamase Producing Acinetobacter spp. Isolated at a Tertiary Care Institute in North West Region of Rajasthan, India
}

\author{
Abhishek Binnani, B.R. Bishnoi, Saroj Meena* and Dhara Singh \\ Department of Microbiology, Sardar Patel Medical College, Bikaner, Rajasthan, India \\ *Corresponding author
}

\begin{abstract}
A B S T R A C T
Acinetobacter causes a wide variety of illness in debilitated and hospitalized patients. Carbapenem resistance in Acinetobacter is an emerging problem and is a cause of concern as many nosocomial infections with Acinetobacter are resistant to most other antibiotics. The present study was aimed to study metallo- $\beta$-lactamase (MBL) production in Acinetobacter species. During one year study (Sep.2010 to Aug.2011), all isolates of

Keywords

Carbapenem resistance, Metallo B-lactamase, A. baumannii

Article Info

Accepted: 18 August 2018 Available Online: 10 September 2018 Acinetobacter obtained from various clinical samples like respiratory, pus, blood and others were included. Antimicrobial susceptibility testing was done by standard Kirby Bauer disk diffusion method. Metallo $\beta$-lactamase (MBL) detection was done by imipenem-EDTA combined disk method. Among 200 isolates, 21 were Acinetobacter spp. Out of these 21, 8 were MBL producing Acinetobacter spp. The MBL producing strains were most frequently recovered from urine $37.5 \%(03 / 08)$ followed by sputum and respiratory tract specimens $25 \%(02 / 08)$, blood $25 \%(02 / 08)$ and pus and other wound discharges $12.5 \%$ (01/08) respectively. MBL producing Acinetobacter spp. were $100 \%$ sensitive to colistin and polimyxin B followed by amikacin $(37.50 \%)$, ceftriaxone and ciprofloxacin (12.50\%) respectively, but highly resistant to ceftazidime, doxycycline, nitrofurantoin, imepenem, meropenem and tobramycin. MBL positive isolates of Acinetobacter spp. showed higher resistance as compared to MBL negative isolates. This study demonstrated that multidrug resistant strains of Acinetobacter are common in tertiary care hospitals. Unwarranted and unrestricted usage of antibiotics is associated with emergence of resistance in nosocomial pathogens. Regular monitoring and documentation of carbapenem resistant is crucial in developing strategies to control infection due to these bacteria.
\end{abstract}

\section{Introduction}

Acinetobacter causes a wide variety of illness in debilitated and hospitalized patients. These bacteria survive for long period in hospital environment and thereby the opportunities for cross infection between patients are enhanced
(Bergogne-Berezin and Towner, 1996). Acinetobacter species play a significant role in the colonization and infection of patients admitted in hospitals.

It has been implicated in variety of nosocomial infections. Acinetobacter 
baumannii is intrinsically less susceptible to antibiotics than Enterobacteriaceae; moreover, it has propensity to acquire resistance. Because of frequent resistance to aminoglycosides, flouroquinolones, ureidopenicillins and third - generation cephalosporins, carbapenems are important agents for managing Acinetobacter infections (Manikal et al., 2000).

The resistance of Acinetobacter baumannii to carbapenem is now a major worldwide issue (Maltezou, 2009; Peymani et al., 2011; Gupta et al., 2006; Yong et al., 2002). The carbapenems are $\beta$-lactam antimicrobial agent with an exceptionally broad spectrum of activity.

Carbapenem resistance in Acinetobacter is an emerging problem and is a cause of concern as many nosocomial Acinetobacter are resistant to most other antibiotics. Metallo-betalactamase (MBL) producing Acinetobacter baumannii has become a growing therapeutic concern worldwide.

The rapid detection of MBL positive isolates is necessary to control infection and to prevent their dissemination. The aim of this study was to determine the prevalence of MBL among carbapenem resistant strains of Acinetobacter species in our hospital.

\section{Materials and Methods}

The one year prospective study was conducted in the department of microbiology. Various clinical samples like, urine, sputum \&respiratory tract specimens, blood, pus \&other wound discharge were processed according to the standard procedures. The isolates were identified as non-fermenting Gram negative bacilli (NFGNB) on the basis of colony characteristics, Gram's staining, motility test, oxidase and alkaline reaction on Triple Sugar Iron agar. All oxidase negative and non-motile NFGNB isolates were further identified by various tests like OF-glucose, arginine dihydrolase, growth at $44^{\circ} \mathrm{C}$, citrate utilization and haemolysis on blood agar (Noyal et al., 2009).

The antimicrobial susceptibility testing was done by Kirby Bauer disc diffusion method using Amikacin $(30 \mu \mathrm{g})$, Ceftazidime $(30 \mu \mathrm{g})$, Ceftriaxone $(30 \mu \mathrm{g})$, Ciprofloxacin $(5 \mu \mathrm{g})$, Cefoperazone $(75 \mu \mathrm{g})$, Colistin $(10 \mu \mathrm{g})$, Doxycycline hydrchloride $(30 \mu \mathrm{g})$, Imipenem $(10 \mu \mathrm{g})$, Meropenem $(10 \mu \mathrm{g})$, Nitrofurantoin (300 $\mu \mathrm{g})$, Piperacillin $(100 \mu \mathrm{g})$, Polymixin $(300 \mu \mathrm{g})$, Tobramycin $(10 \mu \mathrm{g})$, as per CLSI Guidelines (De et al., 2010).

Ceftazidime, Meropenem and Imipenem resistant isolates were selected for the detection of MBL production by Ceftazidime/Meropenem/Imipenem-EDTA combined disc test (Yong et al., 2002).

\section{Results and Discussion}

The present study revealed high proportion of MBL producing Acinetobacter isolates. Respiratory, pus, urine and blood samples collected from patients were found to be the main sources of MBL producing isolates. Early detection and infection control practices are the best defences against these organisms; therefore, systematic surveillance to detect MBL producers is necessary.

It is important to follow antibiotic restriction policies to avoid excessive use of carbapenem and other broad spectrum antibiotics.

This study shows the prevalence of MBL production was higher in Acinetobacter spp. $38.10 \%$. This correlates with other studies by Noyal et al., (2009) where MBL production was higher in Acinetobacter spp. (51\%), De et al., (2010) noticed Acinetobacter spp. (36\%) (Table 1-3). 
Table.1 Distribution of MBL producing Ps. aeruginosa and Acinetobacter spp.

\begin{tabular}{|c|c|c|c|c|}
\hline S. No & Organism & Total numbers & $\begin{array}{c}\text { MBL } \\
\text { producers }\end{array}$ & Percentage (\%) \\
\hline 1 & Acinetobacter Spp. & 21 & 08 & $38.10 \%$ \\
\hline
\end{tabular}

\section{ACINETOBACTER SPP}

TOTAL NO., 21

PERCENTAGE,

38.1

MBL PRODUCER,

\section{8}

TOTAL NO.

MBL PRODUCER

PERCENTAGE

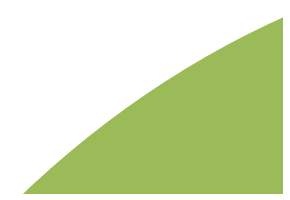

Table.2 Distribution of MBL producing and non MBL producing Acinetobacter spp. isolates from various clinical specimens

\begin{tabular}{|l|l|c|c|c|}
\hline S.N. & \multicolumn{1}{|c|}{ Clinical sample } & $\begin{array}{c}\text { Total } \\
\text { Acinetobacter } \\
\text { spp. isolate }(\%)\end{array}$ & $\begin{array}{c}\text { Acinetobacter spp. } \\
\text { MiBL positive } \\
\text { isolate }(\%)\end{array}$ & $\begin{array}{c}\text { Acinetobacter spp. } \\
\text { MBL negative } \\
\text { isolate (\%) }\end{array}$ \\
\hline 1. & Urine & $06(28.57 \%)$ & $03(37.5 \%)$ & $03(23.08 \%)$ \\
\hline 2. & $\begin{array}{l}\text { Sputum and } \\
\text { respiratory tract } \\
\text { specimens }\end{array}$ & $08(38.10 \%)$ & $02(25 \%)$ & $06(46.15 \%)$ \\
\hline 3. & $\begin{array}{l}\text { Blood } \\
\text { Pus \& other wound } \\
\text { discharges }\end{array}$ & $02(9.52 \%)$ & $01(12.5 \%)$ & $01(7.69 \%)$ \\
\hline 5. & TOTAL & 21 & $02(25 \%)$ & 03 \\
\hline
\end{tabular}




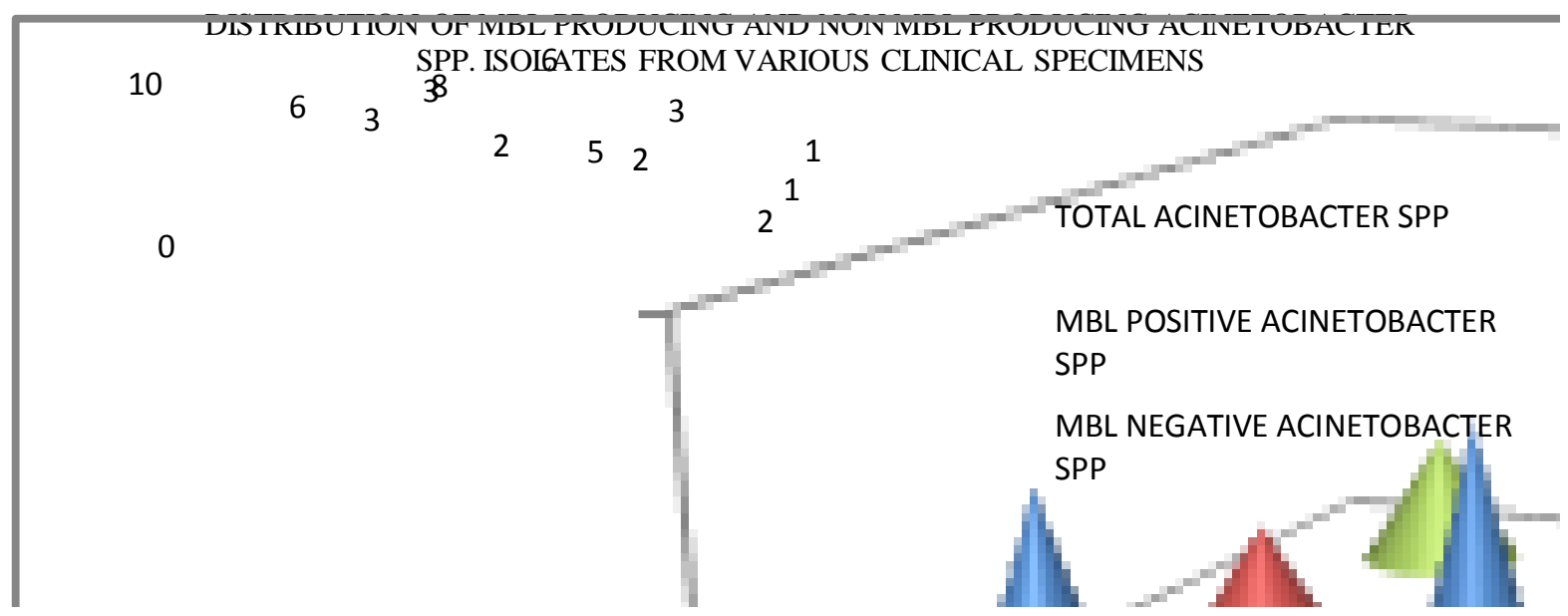

Table.3 Antimicrobial susceptibility pattern of MBL producing and non-MBL producing Acinetobacter spp.

\begin{tabular}{|c|c|c|c|}
\hline $\begin{array}{l}\text { S. } \\
\text { No. }\end{array}$ & Name of drug & $\begin{array}{c}\text { Acinetobacter spp. MBL } \\
\text { positive isolates }(\%)\end{array}$ & $\begin{array}{c}\text { Acinetobacter spp. MBL } \\
\text { negative isolates (\%) }\end{array}$ \\
\hline 1. & Amikacin & $03(37.50 \%)$ & $10(76.92 \%)$ \\
\hline 2. & Ceftazidime & $00(0.00 \%)$ & $09(69.23 \%)$ \\
\hline 3. & Ceftriaxone & $01(12.50 \%)$ & $10(76.92 \%)$ \\
\hline 4. & Ciprofloxacin & $01(12.50 \%)$ & $05(38.46)$ \\
\hline 5. & Colistine & $08(100 \%)$ & $13(100 \%)$ \\
\hline 6. & Doxycycline hydrochloride & $00(0.00 \%)$ & $11(84.62 \%)$ \\
\hline 7. & Imipenem & $00(0.00 \%)$ & $12(92.31 \%)$ \\
\hline 8. & Meropenem & $00(0.00 \%)$ & $07(53.85 \%)$ \\
\hline 9. & Nitrofurantoin* & $00(0.00 \%)$ & $02(33.33 \%)$ \\
\hline 10. & Polymixin-B & $08(100 \%)$ & $13(100 \%)$ \\
\hline 11. & Tobramycin & $00(0.00 \%)$ & $07(53.85 \%)$ \\
\hline
\end{tabular}

* Nitrofurantoin were tested against urinary isolates only.

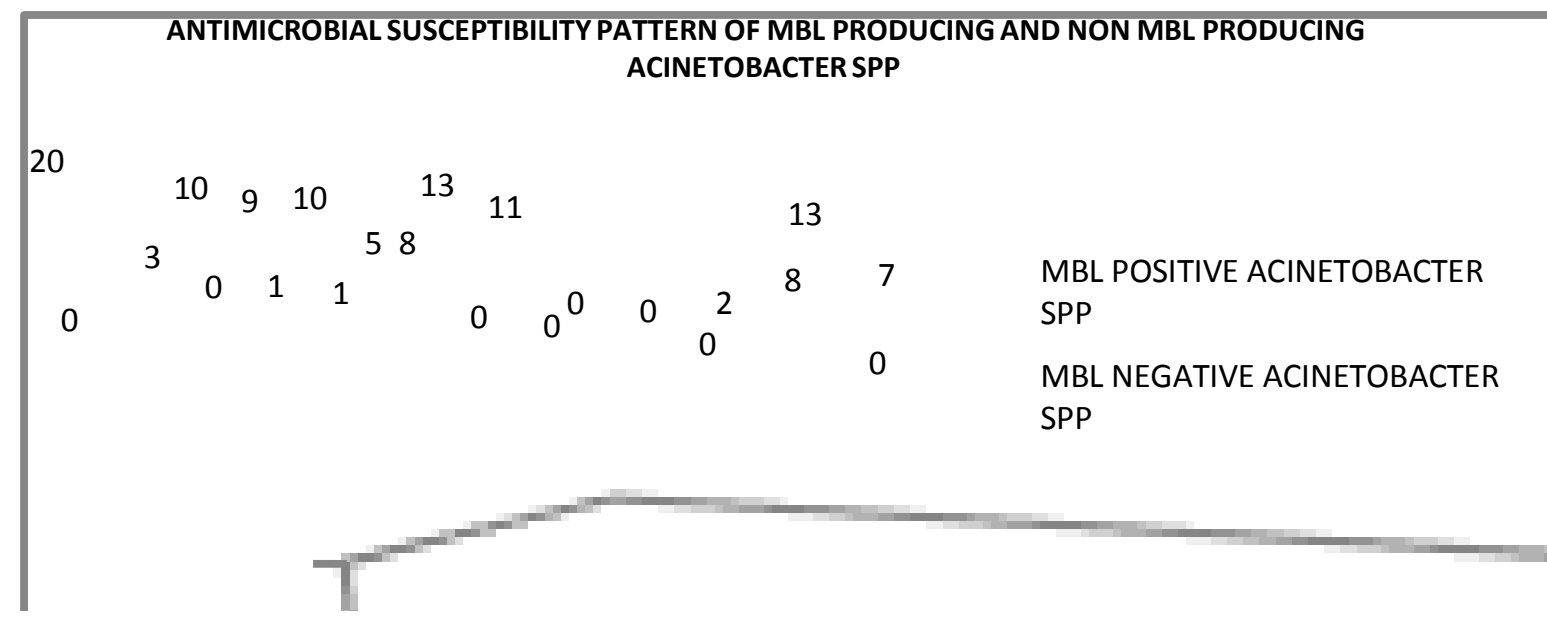


MBL producing Acinetobacter spp. strains were most frequently recovered from urine $37.5 \%$ followed by sputum and respiratory tract specimens $25 \%$, blood $25 \%$ and pus \& other wound discharges $12.5 \%$ respectively. Similar observations were noticed by Kyungwon Lee et al., (2003) where MBL producing Acinetobacter spp. were most frequently obtained from urine $29.2 \%$ followed by sputum $13.3 \%$ and wound $9.9 \%$, Bum Sik Chin et al., (2011) noticed 9.43\% Acinetobacter spp. from urine.

MBL producing Acinetobacter spp. were $100 \%$ sensitive to colistin and polimyxin B followed by amikacin $(37.50 \%)$, ceftriaxone and ciprofloxacin (12.50\%) respectively. Similar results were also observed by De et al., (2010), Fatima Kaleem et al., (2010), Bum Sik Chin et al., (2011)

\section{References}

Bergogne-Berezin E, and Towner KJ. Acinetobacter species as nosocomial pathogens: Microbiological, clinical and epidemiological features. Clin Micro Rev. 1996; 9:148-165.

Bum Sik Chin, Sang Hoon Han, Suk Hoon Choi, Han Sung Lee, Su Jin Jeong, Hee Kyung Choi, Jun Yong Choi, Young Goo Song, Chang Ki Kim, Dongeun Yong, Kyungwon Lee, and June Myung Kim. The Characteristics of Metallo- $\beta$ Lactamase-Producing Gram-Negative Bacilli Isolated from Sputum and Urine. Yonsei Med J 52(2): 351-357, 2011

De AS, Kumar SH, Baveja SM. Prevalence of metallo- $\beta$-lactamase producing Pseudomonas aeruginosa and Acinetobacter species in intensive care areas in a tertiary care hospital. Indian J Crit Care Med. 2010 Oct; 14(4):217-9)

Fatima Kaleem, Javaid Usman, Afreenish Hassan, Aslam Khan. Frequency and susceptibility pattern of metallo-beta- lactamase producers in a hospital in Pakistan. J Infect DevCtries 2010; 4(12): 810-813.

Gupta V, Datta P, Chander J, et al., Prevalence of metallo- $\beta$ lactamase (MBL) producing Pseudomonas spp. and Acinetobacter spp. in a tertiary care hospital in India. J Infect. 2006; 52:311-314.

Kyungwon Lee, Wee Gyo Lee, Young Uh, Gyoung Yim Ha, Jihyun Cho, Yunsop Chong. VIM- and IMP-type metallobeta-lactamase-producing Pseudomonas spp. and Acinetobacter spp. in Korean hospitals.

Maltezou HC. Metallo- $\beta$-lactamases in Gramnegative bacteria: introducing the era of pan-resistance? International Journal of Antimicrobial Agents. 2009; 33:405 e1405 e7.

Manikal VM, Landman D, Saurina G, Oydna E, Lal H, Quale J. Endemic carbapenem resistant Acinetobacter species in Brooklyn, New York: citywide prevalence, inter institutional spread and relation to antibiotic usage. Clin Infect Dis. 2000; 31:101-106.

Noyal, M.J.C., G.A. Menezes, B.N. Harish, S. Sujatha \& S.C. Parija. Simple screening tests for detection of carbapenemases in clinical isolates of nonfermentative Gram-negative bacteria. Indian J Med Res 129, June 2009, pp 707-712

Performance standards for antimicrobial susceptibility testing; seventeenth informational supplement CLSI document. 2007 Jan; 70(1) M-100-S17.

Peymani A, Nahaei MR, Farajnia S, Hasani A, Mirsalehian A, Sohrabi N, et al., High prevalence of metallo-betalactamase-producing Acinetobacter baumannii in a teaching hospital in Tabriz, Iran. Jpn J Infect Dis. 2011; 64:69-71.

Winn W Jr, Allen S, Janda W, Koneman E, Procop G, Schreckenberger $\mathrm{P}$, et al., 
editors. Koneman's Color Atlas and textbook of Diagnostic Microbiology. 6. USA: Lippincott Williams and Wilkins Company; 2006. Nonfermenting Gram negative bacilli; pp. 305-391.

Yong D, Lee K, Yum JH, Shin HB, Rossolini GM, Chong Y. Imipenem-EDTA disk method for differentiation of metallo- $\beta$ lactamase-producing clinical isolates of Pseudomonas spp. and Acinetobacter spp. J Clin. Microbiol., 2002; 40:37983801.

\section{How to cite this article:}

Abhishek Binnani, B.R. Bishnoi, Saroj Meena and Dhara Singh. 2018. Study of Prevalence and Antimicrobial Susceptibility Pattern of Matello-Beta-Lactamase Producing Acinetobacter spp. Isolated at a Tertiary Care Institute in North West Region of Rajasthan, India. Int.J.Curr.Microbiol.App.Sci. 7(09): 2521-2526. doi: https://doi.org/10.20546/ijcmas.2018.709.313 